- Introduces gender-related communication aspects in the dental team, and its significance for workplace management and dental education.

- Increases dentists' awareness of nurses' perception of staff interaction.

- Reduces (nurses') occupational stress and dissatisfaction caused by communication errors and improves the working environment for all in the dental team.

\title{
Dental nurses on perceived gender differences in their dentist's communication and interaction style
}

\author{
R. C. Gorter, ${ }^{1}$ J. C. Bleeker ${ }^{2}$ and R. Freeman ${ }^{3}$
}

\begin{abstract}
Objectives To investigate if dental nurses perceive gender differences in the communication and interaction style used by their dentist in general practice.

Methods Data were collected from 64 Northern Irish dental nurses (70\% response), and from 549 Dutch nurses (41\% response).

Respondents completed the Communication and Working Styles

Questionnaire (CWSO), a self-report questionnaire with 20 items on staff communication and working styles. Using principal component analysis, six distinguishable factors could be extracted: [1] gender-related (four items, Cronbach's $\alpha=0.78$ ), [2] friendly relation (four items, $\alpha=0.66$ ), [3] teamwork (four items, $\alpha=0.44$ ), [4] playfulness (two items, $\alpha=0.69$ ), [5] personal attention (three items, $\alpha=0.60$ ), and [6] business-like (two items, $\alpha=0.32$ ). Factors [3] and [6] were additionally analysed at item level given their low internal consistencies.

Results MANOVA indicated a main effect for dentist's gender $[F(6,541)$ $=4.649, p<0.001]$, and for country $[F(6,541)=37.601, p<0.001]$ on the communication style scales. No interaction effect of gender with country was found. Nurses working with a male dentist had higher scores for the 'gender-related' communications styles, whereas those working with a female dentist had higher scores for 'friendly-relation' and 'personal attention' communication styles. Dutch nurses had higher scores on 'playfulness', whereas Northern Irish nurses had higher scores on 'friendly relation' and 'personal attention' communication styles. Some additional differences were found at item level. The age of the dental nurse explained some differences in communication and working styles $[F(6,541)=2.341, p=0.031)$; younger dental nurses scored significantly higher for 'gender- related' communication and working style. Conclusion Gender of the dentist does influence dental nurses' perceptions of the communication styles used in the primary dental
\end{abstract}

\footnotetext{
${ }^{1 *}$ Associate Professor, ${ }^{2}$ Dentist, Department of Social Dentistry \& Behavioural Sciences, Academic Centre for Dentistry, Universiteit van Amsterdam/Vrije Universiteit Amsterdam, Louwesweg 1, 1066 EA Amsterdam, The Netherlands; ${ }^{3}$ Professor, Dental Public Health and Behavioural Sciences, Queen's University, Belfast, Northern Ireland

${ }^{*}$ Correspondence to: Dr Ronald C. Gorter

Email:R.Gorter@acta.nl
}

\section{Refereed paper}

Accepted 10 November 2005

DOI: $10.1038 /$ sj.bdj.4813848

๑ British Dental Journal 2006; 201: 159-164 care setting. Dental nurses working with female dentists report a style predominantly characterised by 'friendly-relation' and 'personal attention', whereas those working with a male dentist report 'genderrelated' communication and working styles. Given the steadily growing percentage of females entering the dental profession, it is recommended to raise both dentists' and nurses' awareness on gender influences in professional communication by introducing these topics in their respective education.

\section{INTRODUCTION}

During the last few decades there has been an increase in the number of women working in traditionally predominantly male positions. ${ }^{1,2}$ This is particularly true for dentistry, where the proportion of female dentists among general practitioners is steadily growing. Nevertheless, nearly all dental nurses are female. ${ }^{3}$ In The Netherlands, for instance, between 1996 and 2005 the proportion of female general dental practitioners has increased from $18.4 \%$ to $25.1 \% .^{2,4}$ In Northern Ireland, in 2003 some 39\% of the working general dental practitioners were female. ${ }^{5}$ Among the next generations, the proportion of females among dentists is expected to increase further, with at least $50 \%$ of dental students expected to be female. ${ }^{6-8}$ The increasing numbers of women becoming dentists does raise some questions with regard to the communication and interaction patterns that exist between dental staff.

In communication research, gender differences have been subject to extensive study, indicating that women tend to engage in symmetrical, cooperative, emotion focused communication patterns, whereas males show asymmetrical, competitive, information focused patterns. ${ }^{9-12}$ Within dentistry, two studies - conducted by the present authors - examined communication and working styles among dentists and dental nurses in general practice in The Netherlands and Northern Ireland (NI). ${ }^{13,14}$ Qualitative analysis of a series of interviews with male and female Dutch and NI dentists revealed that male rather than female dentists had easier communication and working interactions with their dental nurses. ${ }^{13}$ Irrespective of whether female dentists adopted a 'friendly-like' or a 'business-like' strategy, nurses could neglect their instructions and/or react in a disrupted manner. It was noted that inconsistencies in the hierarchical role the female dentist adopted were the 
basis of their difficulties in the relation to their nurse. Younger female dentists, in particular, reported difficulties in finding a balance between establishing professional authority and being friends with their dental nurse. Male dentists, on the other hand, who operated more strictly within a hierarchical framework, experienced fewer difficulties.

The findings from a second, quantitative, study ${ }^{14}$ concluded that female dentists tended to adopt a 'friendly-like' leadership style, whereas male dentists tended to adopt a 'gender-influenced' interacting style. The 'gender-influenced' interacting style seemed to reflect the playfulness aspect - the flirtatious dimension of the working interaction between male dentist and female nurse. It was apparent that in both countries the predominating factor which affected communication and working styles between dentist and dental nurse was gender.

The understanding of staff communication patterns in dental practice needs to be improved if dentist-dental nurse working interactions are to be relatively stress-free. In order to achieve this goal it is necessary to examine the perceptions of communication styles, not only from the perception of the dentist but also from the perspective of the dental nurse. While there is a small line of research on dental nurses' social functioning, the majority of this research is focused on occupational stress and job satisfaction and not explicitly on communication patterns. ${ }^{15}$ Nevertheless, it appears that at the centre of nurses' job dissatisfaction are poor working relationships, and inappropriate communications and interactions between dentists and nurses. ${ }^{16,17}$ The need for clear and structured communication frameworks in dental practice has been suggested to improve nurses' job satisfaction. ${ }^{17-}$

${ }^{20}$ In order to achieve such frameworks, staff communication needs to be analysed, for instance by examining dental nurses' perceptions of the communication and working styles used by male and female dentists.

To summarise: the growing influx of female dentists, the welldescribed differences in communication patterns between males and females, the need for clearly structured communication frameworks, plus the fact that among male and female dentists interesting results were found, all justify analysis of communication patterns from the nurses' perspective. The aim, therefore, of the present study was to investigate if dental nurses perceive gender differences in the communication styles used by male and female dentists in general practice. It was hypothesised that dental nurses would describe communication and working styles with female dentists to be more 'friendly-like', whereas communication styles with male dentists would be described to be more 'business-like'. Furthermore, by conducting the study in more than one country, an indication of possible country specific cultural influences could be obtained.

\section{METHOD}

\section{The sample}

In order to allow for greater generalisability of the findings, it was decided to include Dutch and Northern Irish nurses. The rationale for these two countries is, apart from being the researchers' home countries, that the proportion of males compared with females working in general practice differs substantially between The Netherlands and NI. ${ }^{2,4,5}$ Since no registers of nurses' home addresses were available and answering the questionnaires within the presence of the dentist was to be avoided, another way of approaching the nurses was chosen. A convenience sample of nurses attending continuing education conferences were invited to take part. In The Netherlands, 1,348 dental nurses attended a conference in Amsterdam. In NI, fifty dental nurses who attended a professional course in Belfast were asked to participate, plus another 48 nurses who could not attend the course.

\section{MATERIALS}

\section{Development of the Communication and Working Styles Questionnaire (CWSO))}

The CWSQ was developed using three sources of information. The first source was a literature search exploring PubMed indexed literature, ranging from 1967 to 2003. This revealed no previous examples of explicit dentist-nurse communication and working styles studies, described from the nurses' perspective. In some studies though, suggestions for better cooperation were given, which included themes that were considered useful for the present communication style study. The second source of information was a series of in-depth interviews with a focus group of selected dental nurses. The semi-structured interviews were summarised and themes were selected by the present authors for inclusion as questionnaire items. The final source for the questionnaire was two recently conducted studies among dentists on this topic. ${ }^{13,14}$ The instrument used among dentists contained four subscales on communication styles with internal consistencies (Cronbach's alpha) ranging from 0.83 to 0.87. Using all these sources, the present CWSQ was constructed. In order to obtain an acceptable degree of cultural equivalence, a parallel version of the questionnaire, in Dutch, was prepared by a licensed translation office (Vrije Universiteit, Amsterdam). The final version of the CWSQ was piloted in both The Netherlands and NI to assess ease of understanding and completion.

The CWSQ consists of two parts. The first part examines the dental nurses' demographic profile and her working environment (the practice characteristics). The second part consists of 20 items on communication and working styles used by dentists when interacting with dental nurses.

\section{Psychometric properties of the CWSO}

Using principal component analysis, after varimax rotation, six factors were extracted from the 20 communication items with Eigenvalue $>1$, explaining 53\% of the variance. The internal consistencies of the six factors, however, varied from Cronbach's alpha 0.32 to 0.78 . One item (\# 16) could not be included in any factor. Since no preceding studies were found on this topic to relate to, it made sense to describe all factors, including the weaker ones, as communication and working style scales. The two scales with alpha $<0.60$ were additionally analysed at item level. In Table 1 the various individual items and scales are presented with their communication and working style labels, together with Cronbach's alphas and interscale correlations.

\section{Administration of the CWSO}

In The Netherlands 1,348 questionnaires were distributed, with help of the organising bureau, at a one day national dental nurses conference in Amsterdam, November 2003. A brief explanation about purpose, consent and way of returning (boxes were placed at the lecture hall exit gates and some market stands) was given during one of the central morning lectures. In Northern Ireland, 50 consents and questionnaires were distributed at an equivalent compulsory professional education meeting for dental nurses in Belfast, October 2003. A further 48 consent forms and questionnaires were distributed among all dental nurses who were registered for the meeting but were unable to attend the study day. In all cases forms were to be returned anonymously.

\section{Statistical analysis}

Apart from item level mean scores, indices were constructed by computing average scores for each of the interaction style scales. Differences in mean scores on the communication and working scales between gender of dental nurses' dentist and country were assessed using a single, multivariate, analysis of variance (using SPSS's GLM). Weaker scales (by which is meant scales with low 
Table 1 Communication and Working Styles Questionnaire (CWSO): scales (means, standard deviations and reliabilities) and items (means, standard deviations and factor loadings). NB: where dentist is referred to as 'he' this can also be read 'she'

\begin{tabular}{|c|c|c|c|c|}
\hline Item & & Cronbach's alpha & Factor loading & Mean (SD) \\
\hline & Gender related & 0.78 & & $2.0(0.9)$ \\
\hline 17 & $\begin{array}{l}\text { I accept the leadership of a male dentist rather than the leadership of a female } \\
\text { dentist. }\end{array}$ & & 0.747 & $1.74(1.1)$ \\
\hline 18 & $\begin{array}{l}\text { In my opinion the best working combination in a dental practice is a male dentist } \\
\text { with a female dental nurse. }\end{array}$ & & 0.886 & $1.93(1.2)$ \\
\hline 19 & $\begin{array}{l}\text { In my opinion the best working combination in a dental practice is a female dentist } \\
\text { with a female dental nurse. }\end{array}$ & & 0.662 & $1.86(1.0)$ \\
\hline \multirow[t]{2}{*}{20} & I would rather work with a male than a female dentist. & & 0.783 & $2.33(1.3)$ \\
\hline & Friendly relation & 0.66 & & $3.3(0.8)$ \\
\hline 1 & The best way to work with a dentist is to be friendly. & & 0.350 & $4.39(0.8)$ \\
\hline 5 & I would talk about personal problems with a dentist. & & 0.759 & $2.62(1.2)$ \\
\hline 6 & $\begin{array}{l}\text { I think that talking about private matters with a dentist would disturb my working } \\
\text { relationship with him. }\end{array}$ & & -0.716 & $2.38(1.1)^{*}$ \\
\hline \multirow[t]{2}{*}{7} & I think you should count on your dentist as a friend. & & 0.677 & $2.63(1.3)$ \\
\hline & Playfulness & 0.69 & & $3.1(1.0)$ \\
\hline 14 & $\begin{array}{l}\text { If there was friction or irritation between a dentist and me, I would solve this by } \\
\text { relieving the tension by humour. }\end{array}$ & & 0.851 & $3.25(1.1)$ \\
\hline \multirow[t]{2}{*}{15} & $\begin{array}{l}\text { If there was friction or irritation between a dentist and me, I would solve this by the } \\
\text { 'playful atmosphere' there can be between a dentist and a dental nurse. }\end{array}$ & & 0.828 & $3.02(1.1)$ \\
\hline & Personal attention & 0.60 & & $3.9(1.0)$ \\
\hline 9 & $\begin{array}{l}\text { If something was bothering me about my dentist's work I think I should talk about it } \\
\text { with him. }\end{array}$ & & 0.746 & $4.05(1.3)$ \\
\hline 10 & $\begin{array}{l}\text { I think a dentist should tell the dental nurse if something is bothering him when they } \\
\text { work together. }\end{array}$ & & 0.647 & $4.17(0.9)$ \\
\hline \multirow[t]{2}{*}{13} & $\begin{array}{l}\text { If there was friction or irritation between a dentist and me, I would solve this by } \\
\text { paying personal attention to his feelings. }\end{array}$ & & 0.481 & $3.58(1.0)$ \\
\hline & Teamwork & 0.44 & & $3.3(0.7)$ \\
\hline 3 & As a dental nurse I know immediately, when a dentist needs my assistance. & & 0.348 & $4.45(0.6)$ \\
\hline 8 & I think that it would be good to have regular meetings about (...) with your dentist. & & 0.448 & $2.88(1.4)$ \\
\hline 11 & $\begin{array}{l}\text { I think that if something was bothering me when I am working with a dentist, I } \\
\text { should be able to report it an intermediary, eg the practice manager or principal } \\
\text { dentist. }\end{array}$ & & 0.701 & $2.45(1.4)$ \\
\hline \multirow[t]{2}{*}{12} & If I work with a new dentist it may take a while until we work as a team. & & 0.609 & $3.54(1.0)$ \\
\hline & Business-like & 0.32 & & $2.4(0.9)$ \\
\hline 2 & The best way to work with a dentist is to be business-like. & & 0.815 & $2.87(1.2)$ \\
\hline 4 & The dentist I work with in my opinion too often tells me what to do. & & 0.502 & $1.89(1.0)$ \\
\hline
\end{tabular}

internal consistency) were not expected to systematically influence the analysis and for that reason these were also included. An additional comparison of means (t-tests) at item level was conducted for the two scales with alphas $<0.60$. MANOVA included dental nurses' age as a covariate. Product moment correlation coefficients were calculated between communication style scale scores and some person and practice characteristics.

\section{RESULTS}

\section{The sample}

Of the 1,348 questionnaires distributed in The Netherlands, 549 forms were collected in boxes at the end of the meeting (41\% response). Eight of these were returned blank. The overall response rate for The Netherlands was 40\%. 
All fifty participants at the Belfast region course returned the questionnaire before finishing the course (100\% response). Four forms were left blank. Of the questionnaires distributed among those who could not attend, 34 forms were returned (70\% response). Reasons for non-completion included being either ill at home or on pregnancy leave during the data collection period. The overall response rate for NI was $86 \%$.

\section{Participants' demographic characteristics}

Table 2 provides an overview of the demographic characteristics of the participants. Of the Dutch dental nurses, five were male $(0.9 \%)$. In NI, one respondent was male $(1.2 \%)$. Their data were excluded from further analysis.

\section{Communication and working styles}

Mean scores and standard deviations of all scales on the CWSQ are presented in Table 1 . The results of a MANOVA indicated that differences in mean scores for communication and working styles existed between dental nurses working with a male dentist as compared with those working with a female dentist $[\mathrm{F}(6,541)$ $=4.649, \mathrm{p}<0.001]$. Univariate analysis showed that dental nurses working with a male dentist had significantly higher mean scores for 'gender-related' communication and working style compared with working with a female dentist $[\mathrm{F}(1,546)=$ $11.472, p=0.001]$. Dental nurses working with a female dentist had significantly higher mean scores for 'friendly-relation' communication and working style $[\mathrm{F}(1,546)=7.017, \mathrm{p}=0.008]$, and for 'personal attention' $[\mathrm{F}(1,546)=8.933, \mathrm{p}=0.003]$.

Main effects were also found for country of practice with regard to communication and working style scores $[\mathrm{F}(6,541)=37.601, \mathrm{p}<$ $0.001]$. Univariate analysis showed that NI dental nurses reported significantly higher mean scores for 'friendly-relation' communication and working style $[\mathrm{F}(1,546)=6.919, \mathrm{p}=0.009]$, for 'personal attention' $[\mathrm{F}(1,546)=11.807, \mathrm{p}=0.001]$, 'teamwork' $[\mathrm{F}(1,546)=$ $189.982, \mathrm{p}<0.001]$, and 'business-like' communication $[\mathrm{F}(1,546)$ $=15.633, \mathrm{p}<0.001]$. Dutch dental nurses reported significantly higher mean scores for 'playfulness' $[F(1,546)=3.919, p=$ $0.048]$. There was no country of practice effect for 'gender related' communication and working style scores.

MANOVA revealed no interaction effect between gender of the dental nurses' dentist and country on any of the communication working style scores $[\mathrm{F}(6,541)=1.543$, NS]. The age of the dental nurse acted as a significant covariate $[\mathrm{F}(6,541)=2.341, \mathrm{p}=0.031]$. Univariate analysis showed that younger dental nurses had significantly higher mean scores for gender-related communication and working style scores $[\mathrm{F}(1,546)=10.818, \mathrm{p}=0.001]$.

Since the scales 'teamwork' and 'business-like' communication style showed low internal consistencies (alpha $<0.60$ ), the items that were part of these scales (and item 16 that was not included in any scale) were inspected separately. With regard to gender of the dentist, only items 8 ('I think that it would be good to have regular meetings about (...) with your dentist') and 16 ('I think there is often a flirting element in the working relationship between a male dentist and a female dental nurse') showed significant gender differences: that is, dental nurses working with a female dentist showed significantly higher mean scores for items 8 and 16. With regard to country of practice, on all these separately inspected items NI dental nurses showed higher mean scores compared with Dutch dental nurses.

\section{CONCLUSION AND DISCUSSION}

The aim of the present study was to investigate if dental nurses perceived gender differences in communication and working styles with their dentist. It was hypothesised that dental nurses working with a male dentist would report differences in communication and working style when compared with those working
Table 2 Person and practice characteristics respondents

\begin{tabular}{|c|c|c|}
\hline & The Netherlands & Northern Ireland \\
\hline $\begin{array}{l}\text { Gender nurse } \\
\text { Male } \\
\text { Female }\end{array}$ & $\begin{array}{l}0.9 \% \\
98.4 \%\end{array}$ & $\begin{array}{l}1.2 \% \\
98.8 \%\end{array}$ \\
\hline $\begin{array}{l}\text { Age nurse in years } \\
\text { Minimum } \\
\text { Maximum } \\
\text { Mean (SD) }\end{array}$ & $\begin{array}{l}17 \\
58 \\
34.6(9.2)\end{array}$ & $\begin{array}{l}18 \\
58 \\
32.3(9.2)\end{array}$ \\
\hline $\begin{array}{l}\text { Working hours per week } \\
\text { Minimum } \\
\text { Maximum } \\
\text { Mean (SD) }\end{array}$ & $\begin{array}{l}4 \\
50 \\
25.9(9.3)\end{array}$ & $\begin{array}{l}- \\
- \\
-\end{array}$ \\
\hline $\begin{array}{l}\text { Gender dentist } \\
\text { Male } \\
\text { Female }\end{array}$ & $\begin{array}{l}76.1 \% \\
22.6 \%\end{array}$ & $\begin{array}{l}72.0 \% \\
26.8 \%\end{array}$ \\
\hline $\begin{array}{l}\text { Age dentist in years } \\
\text { Minimum } \\
\text { Maximum } \\
\text { Mean (SD) }\end{array}$ & $\begin{array}{l}24 \\
67 \\
44.7(8.1)\end{array}$ & $\begin{array}{l}- \\
- \\
-\end{array}$ \\
\hline $\begin{array}{l}\text { Practice organisation } \\
\text { Solo practice } \\
\text { Group practice } \\
\text { Health care centre } \\
\text { Hospital } \\
\text { Other }\end{array}$ & $\begin{array}{l}45.9 \% \\
45.7 \% \\
4.0 \% \\
1.6 \% \\
2.4 \%\end{array}$ & $\begin{array}{l}41.5 \%{ }^{*} \\
* \\
8.5 \% \\
48.8 \% \\
1.2 \%\end{array}$ \\
\hline $\begin{array}{l}\text { Nurse is dentist's life partner } \\
\text { Yes } \\
\text { No }\end{array}$ & $\begin{array}{l}2.4 \% \\
96.7 \%\end{array}$ & $\begin{array}{l}0 \% \\
100 \%\end{array}$ \\
\hline
\end{tabular}

*In Northern Ireland no distinction between solo and group practice was made

with a female dentist. This hypothesis was confirmed. Dental nurses working with a male dentist experienced a stronger 'gender-related' communication and working style, whereas those working with a female dentist experienced a stronger 'friendlyrelation' and 'personal attention' communication and working style. The hypothesis that some country differences would occur was also confirmed as Dutch dental nurses reported a stronger 'playfulness' interaction, whereas NI dental nurses reported a stronger 'friendly-relation' and 'personal attention' style. No interaction effect was found between country and gender of the dentist. At item level, some additional gender and country differences were found. The age of the dental nurse explained some differences, with younger dental nurses having higher scores for 'gender-related' communication and working style, suggesting that they had adopted a more traditional and subservient position with regard to the male dentist as 'boss'.

Previous research has shown that male and female dentists also differ in the way they perceive communication with the dental nurse. ${ }^{13,14}$ Male dentists were reported to be more businesslike and gender-influenced in their style, whereas female dentists were reported to be more friendly-like and professionally interacting. The present results confirm these findings from the dental nurses' perspective. They also reported that male dentists tend to be more businesslike and female dentists to be more friendly-like in their communication and working style. With regard to country differences the comparison is a little less straightforward. Dentists from The Netherlands reported a stronger professional interacting style than their NI colleagues, whereas in the present research Dutch dental nurses reported a stronger 'playfulness' style, and NI dental nurses reported a stronger 'friendly relation' and 'personal attention' style.

One limitation of the present study is the fact that some scales, notably 'business-like' style and 'teamwork', showed internal 
consistencies that did not reach acceptable psychometric levels. The present study is the first time the Communication and Working Styles Questionnaire (CWSQ) has been used among nurses, after proving its usefulness among dentists in a previous study, ${ }^{14}$ and it is open for further development. For reasons of exploration all scales were included in the analyses, but with regard to the weaker scales any interpretation should be limited to item level. The challenge for future research clearly is to work on these particular scales, either by rephrasing the items or by adding new ones, in order to obtain satisfying psychometric values.

In an additional analysis at item level, it appeared that on two items nurses working with a female dentist had higher scores, one of them being item 8 on the benefits of having regular work meetings. This is interesting, since from previous research among dentists on this topic, it was already argued that incorporating appraisal and organisational procedures among staff would be helpful. ${ }^{14}$ For the majority of dental practices it was not routine to have this. Especially in the light of the risk of role confusion between a female dentist and nurse - shifting from a friendly style to a business-like style and vice versa - it was argued that clear job descriptions and regular evaluation meetings would be beneficial in avoiding job dissatisfaction. From the present data, it is noteworthy that especially those working with a female dentist appear to express the need for this.

On the whole, with the exception of the 'playfulness' scale, NI nurses showed higher mean scores. This was also true for the items tested regardless of scale. This could be interpreted as indicating that the communication styles measured are more strongly present in the NI situation. However, one should always be careful with straightforward cross cultural comparisons, as has been shown in other fields of research. ${ }^{21}$ Even when incorporating careful procedures for obtaining cultural equivalence of the instrument, cultural differences in answering tendencies may interfere. On the other hand, given the tendency as described, the fact that 'playfulness' was higher among Dutch nurses could very well be an indicator that interaction patterns in Dutch practices are less formal than those in Northern Ireland.

From research on dental nurses' job satisfaction, it was shown that nurses who reported that they could not communicate about their feelings with the dentist also described this as influencing their job satisfaction negatively. ${ }^{22}$ Since dissatisfaction is a key motive to leave practice for nurses ${ }^{16}$ and staff relations is a key work stressor for dentists, ${ }^{23}$ it is beneficial to both professions to work on satisfying communication conditions. In the present study this topic was captured with the 'friendly relation' style scale. Nurses working with female dentists showed significantly higher mean scores on this scale. In future research it would be interesting to investigate if there is a positive correlation between this communication style and job satisfaction among nurses. Furthermore, since this communication style was reported by those working with a female dentist more strongly, it raises the question of whether nurses working with a female dentist do experience more job satisfaction in general.

Apart from including job satisfaction, some other aspects are also worth taking into account in future surveys. For example, in the present study, no information was obtained with regard to sexual orientation. Obviously, the heterosexual/homosexual orientation of either the dentist or the nurse could influence the outcomes. Other aspects that could be included are dentists' age, or number of dental staff members.

Another aspect that needs to be taken into consideration is generalisability. In the present study, the majority of respondents were Dutch nurses, visiting a non-obligatory conference. Although the response rate was only 40\% in Amsterdam, the respondents reflected the average Dutch assistant in a number of ways: 23\% of the respondents worked with a female dentist, and 23\% of the Dutch dentists were also female in 2003. ${ }^{24}$ Furthermore, the nurses' age also warranted a reliable reflection of the average Dutch nurse. However, in the present study, nurses working in a solo practice were underrepresented: $46 \%$ with this background, whereas in 2000 up to 70\% of the Dutch dentists were described as solo practitioners working with one or two assistants. ${ }^{2}$ Within NI, the high response rate itself guaranteed a representative description. Nevertheless, it cannot be excluded that those voluntarily visiting a conference differ from those who do not. Perhaps the nurses visiting the conference have better working relations with their employer than the ones who did not? It must be kept in mind that in many cases the dentist will have paid for the conference entrance. Whereas no gender of the dentist-country interaction effect was found, the selection of NI nurses followed a different procedure and therefore it cannot be excluded that selection procedure may have influenced country differences. Future surveys further revealing staff communication aspects will have to consider these points.

Professional communication skills are undergraduate curriculum requirements in both The Netherlands and the UK, ${ }^{19,25}$ as in many other countries. However, the content of the communication skills training is usually focused on dentist-patient communication. Given the tendency for a growing number of staff to be involved in dental practices, mastering basic team communication skills seems to become a necessary undergraduate dental competence. Dental schools should consider including management skills (such as having job feedback meetings, conflict management, and leadership skills) in the curricula. With regard to leadership skills, it is worth mentioning that role confusion easily develops when dentists shift from a friendly seeking to a more authoritative approach. Younger female dentists in particular experience difficulties in authority as a result of shifting between friendly and more directive communication patterns, sometimes causing staff conflict. ${ }^{13}$ From this study it can be learned that an understanding of gender differences in communication patterns can be a valuable element to achieve in these courses. It goes without saying that these topics are also relevant for the dental nurses' education.

Summarising the present study, it can be stated that, according to dental nurses, the communication and working style between dentist and nurse in practices with a male dentist is more genderrelated than female dentists' practices, especially when the nurse is relatively young. Furthermore, in practices with a female dentist the communication and working style is more friendly and contains more personal attention, when compared with male dentists' practices. Some country differences between NI and The Netherlands were found. Given the steadily growing percentage of females entering the dental profession, it is recommended that both dentists' and nurses' awareness of gender influences in professional communication are raised by introducing these topics in their respective education.

1. Murray J J. Better opportunities for women dentists: a review of the contribution of women dentists to the workforce. Br Dent J 2002; 192: 191-196.

2. de Putter $C_{1}$ den Dekker J. Dental health care. In van Rooij E, Droyan Kodner L, Rijsemus T, Schrijvers G (eds) Health and health care in The Netherlands. pp 123-131. Maarssen: Elsevier Gezondheidszorg, 2002.

3. Zillen PA, Mindak M. World health demographics. Int Dent J 2000; 50: 194-197.

4. Dutch Dental Association (NMT). General dental practitioners younger than 65 years of age, with a dental office address in The Netherlands (unpublished data). Nieuwegein: NMT, 2005.

5. Central Service Agencies. Proportion of women dentists in general dental practice in Northern Ireland. Belfast: CSA, 2003.

6. Sinkford J C, Valachovic R W, Harrison S. Advancement of women in dental education: trends and strategies. J Dent Educ 2003; 67: 79-83.

7. Steward F M J, Drummond J R. Women and the world of dentistry. Br Dent J 2000; 188: 7-8

8. Seward M. The gender challenge. Br Dent J 2000; 189: 525

9. Fast J, Fast B. Talking between the lines. New York: The Viking Press, 1979. 
10. Tannen D. You just don't understand: women and men in conversation. New York: Quill, 2001.

11. Aries E. Men and women in interaction: reconsidering the differences. New York: Oxford University Press, 1996.

12. Gjerberg E, Kjølsrød L. The doctor-nurse relationship: how easy is it to be a female doctor co-operating with a female nurse? Soc Sci Med 2001; 52: 189-202.

13. Freeman $R$, Gorter $R$, Braam $A$. Dentists interacting and working with female dental nurses: a qualitative investigation of gender differences in primary dental care. BrDent J 2004; 196: 161-165.

14. Gorter R C, Freeman R. Dentist-assistant communication style: perceived gende differences in The Netherlands and Northern Ireland. Community Dent Oral Epidemiol 2005; 33: 131-140.

15. Butters J M, Willis D 0. Satisfaction level of dental office personnel. Gen Dent 1993; 41: 236-240.

16. Burman D, Locker D. Ontario dental assistants' job satisfaction: relationship to work stress and intention to change jobs. J Can Dent Assoc 1990; 56: 617-620.

17. Gibson $B$, Freeman $R$, Ekins $R$. The role of the dental nurse in general practice.
BrDent J 1999; 186: 213-215

18. Schwartz S. Motivating the dental staff. Dent Clin NAm 1988; 32: 35-45.

19. Humphris G, Ling M S. Behavioural sciences for dentistry. pp 68. Liverpool: Churchill Livingstone, 2000.

20. Kay E J, Thisley S R. Communication and the dental team. London: Stephen Hancocks Limited, 2004.

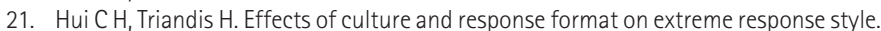
J Cross Cult Psychol 1989; 20: 296-309.

22. Locker D. Work stress, job satisfaction and emotional well-being among Canadian dental assistants. Community Dent Oral Epidemio/ 1996; 24: 133-137.

23. Gorter R C. Burnout among dentists; identification and prevention. Amsterdam: University of Amsterdam, 2000. Academic Thesis.

24. Dutch Dental Association (NMT). General dental practitioners younger than 65 years of age, with a dental office address in The Netherlands (unpublished data). Nieuwegein: NMT, 2003.

25. Gorter R C. Eijkman M A J. Communication skills training courses in dental education Eur J DentEduc 1997: 1: 143-147. 